\title{
Adaptation and Validation of the Diabetes-39 Quality-of-Life Questionnaire for the Moroccan Population
}

\author{
Adarmouch $L^{1,2 *}$, Sebbani $M^{1,2}$, Elansari $N^{3}$ and Amine $M^{1,2}$ \\ ${ }^{1}$ Clinical Research Unit, Mohammed VI University Hospital, Marrakech, Morocco \\ ${ }^{2}$ Community Medicine and Public Health Department, PCIME Laboratory, School of Medicine, Cadi Ayyad \\ University, Morocco \\ ${ }^{3}$ Department of Endocrinology and Diabetology, Mohammed VI University Hospital, Marrakech, Morocco
}

*Correspondence: Latifa Adarmouch, Clinical Research Unit, Mohammed VI University Hospital, Marrakech, Morocco

Received on 17 January 2020; Accepted on 17 April 2020; Published on 22 April 2020

Copyright (C) 2020 Adarmouch L, et al. This is an open access article and is distributed under the Creative Commons Attribution License, which permits unrestricted use, distribution, and reproduction in any medium, provided the original work is properly cited.

\begin{abstract}
Objective: To translate and adapt to the Moroccan context the diabetes-39 questionnaire, and to assess the psychometric properties of the adapted version among Moroccan patients with diabetes.

Materials and Methods: The questionnaire was translated from English to spoken Arabic, then back translated to English. A consensus meeting discussed discrepancies and major changes. The adapted version was administered to 92 patients with type 2 diabetes to assess its psychometric properties. Inter-item correlation, item-to-dimension correlation, and Cronbach's alpha were calculated to assess internal consistency. Additionally, construct validity was assessed using means comparison of domains scores according to the general perception of the quality of life and the perception of disease severity.

Results: Participants' mean age was $56.4 \pm 10.9$. The sample was constituted predominantly by women. Cronbach's alpha ranged from 0.65 for "social burden" and 0.93 for "diabetes control". Items showed a higher correlation with their own domain as compared to other domains. Higher scores of the five domains of the diabetes-39 were associated with the perception of lower quality of life and higher disease severity.

Conclusion: The results of this study support the reliability and validity of the Moroccan version of the diabetes-39 questionnaire. They justify its use and further assessment among our patients with diabetes.
\end{abstract}

Keywords: cross-cultural adaptation, validation, psychometric properties, diabetes-39, Morocco 


\section{Introduction}

Worldwide and national figures of diabetes mellitus are alarming. According to the International Diabetes Federation, 1 in 11 adults were living with diabetes worldwide in 2019 [1, 2]. In Morocco, the prevalence of diabetes increased over the years from $6.6 \%$ in 2000 to $12.4 \%$ in 2016 [3, 4]. With the increasing prevalence of diabetes and its complications as well as the explosion of related costs, challenges to efficient disease management are key elements to consider for diabetes control [5]. Part of these challenges includes considering the active role the patient has to play in his disease management. This emphasizes psychological and social along with biological dimensions of health and disease and corresponding self-management support interventions [6-8]. In Morocco, recent data report an increase in the prevalence of the disease and insist on the challenges to its management $[4,9]$.

Measuring health as it is perceived by the patient has gained interest during the past decades. Health outcomes from the patient's perspective have an even higher significance in the management of chronic diseases such as diabetes. Among these measures of subjective health, quality of life occupies an important place as a key outcome for diabetes management [10]. Literature is abundant in an attempt to characterize how diabetes-related quality of life is determined by the presence of comorbidity, the onset of a complication or the treatment regimen; and how interventions could improve it [11,12]. Many questionnaires, including generic and specific questionnaires, are used and can be combined to measure the quality of life among patients with diabetes [13, 14]. Among diabetes-specific quality of life scales, "Diabetes-39" is a scale developed by Boyer and Earp [15]. It is a multi-dimensional scale exploring several aspects of diabetes-related quality of life. Previous literature suggests interesting psychometric properties for the diabetes-39 scale $[13,14,16,17]$. This questionnaire was used to assess the quality of life among patients with diabetes in different contexts [18-20].

Most quality of life scales are developed in developed countries in English which represents a challenge for quality of life assessment among non-English speaking populations. It is not recommended to develop new questionnaires to accommodate different contexts and cultures for two reasons: the process of questionnaire development is long and complicated, and, the use of different questionnaires to assess the same outcome makes it difficult to compare results across different settings and to efficiently conduct multicenter studies. To allow for international comparisons of research results, the cross-cultural adaptation of these scales is a more interesting approach [21]. It is a process of translation that takes into account the particularities of the new context of use, followed by a validation of the adapted questionnaire through an examination of its psychometric properties.

The diabetes-39 has been translated and adapted to several languages and contexts including classical Arabic in Jordan [22-25]. Nevertheless, to our knowledge, there is no validated version of the diabetes-39 questionnaire for the Moroccan context. Thus, the objective of this study were: to translate and adapt to the Moroccan context, the diabetes39 questionnaire, and to assess the psychometric properties of the adapted version among Moroccan patients with diabetes.

\section{Materials and Methods}

\section{The diabetes-39 questionnaire}

It is a quality of life scale designed for patients with type 1 and type 2 diabetes; regardless of their treatment regimen. It includes 39 items divided into five domains: a) energy and mobility (15 items), b) diabetes control (12 items), c) social burden (5 items), d) anxiety and worry (4 items) and, e) sexual functioning (3 items) [15]. It allows patients to rate their quality of life during the last month on a scale of 1 to 7 for each item. A score of 0 to 100 is obtained. Scores close to 100 indicate an impaired quality of life; on the other hand, scores close to 0 indicate a better quality of life. 


\section{Translation and cross-cultural adaptation}

After obtaining the agreement from the developers of the questionnaire, the adaptation process was carried out following available recommendations [21]. Two translators whose mother tongue is Arabic performed two independent translations from English; which allowed obtaining two versions of the questionnaire in Moroccan spoken Arabic. Following discussions between translators and the research team, a consensual version was drafted and then, proposed for back translation from spoken Arabic to English which was carried out by a third translator.

A consensus meeting brought together health professionals, patients, two methodologists, translators and a linguist. The purpose of the meeting was to discuss the proposed Moroccan version in light of discrepancies between the original version of the questionnaire and the back translated version as well as comments from the translators and the rest of the group. A pre-test was conducted with a patient with type 2 diabetes to ensure that the translated questionnaire is understood by the target population.

\section{Assessment of psychometric properties}

The study was conducted among a sample of adult patients with diabetes. The diagnosis of diabetes had to be carried out for at least 6 months. Patients with mental disorders or unable to speak Moroccan dialect were excluded. Patients were recruited from a patient's organization in the Marrakech region. During regular meetings and activities of the patients' organization such as disease self-management educational sessions; patients were approached and provided with information about the study. Consenting individuals were then invited to respond to the survey. We attempted to recruit the maximum of consenting individuals for this survey as recommended [26]. The questionnaire was administered by trained interviewers who were advised to read the items without attempting to explain or paraphrase the content. Data concerning age, sex, education, health insurance, disease duration, treatment regimen and complications were also recorded. The most recent glycated hemoglobin level was recorded. Finally, two items were used to assess the general perception of the quality of life and the perception of disease severity.

Data analysis initially consisted of a description of the sample characteristics using means and standard deviation for quantitative variables and frequencies and percentages for categorical variables. Cronbach's alpha was calculated to assess internal consistency for the different dimensions. Spearman's correlation coefficient was used to assess interitem correlation and item-to-domain correlation. To test for construct validity, scores means for the five dimensions were compared regarding the general perception of the quality of life and the perception of disease severity using the Mann-Whitney test. We hypothesized that higher scores of the dimensions would be associated with the perception of lower quality of life and, of higher disease severity. The significance level was set at $5 \%$.

\section{Results}

\section{Cross-cultural adaptation}

As a result of the trans-cultural translation and adaptation process, a spoken Arabic version was proposed for psychometric evaluation for use among Moroccan diabetic patients. Due to the characteristics of this population, especially the relatively elderly population of diabetics, and a high proportion of illiteracy, the questionnaire was designed to be administered by investigators rather than being self-administered. It was also recommended to use a scale of 1 to 5 for responses instead of 1 to 7 in the original scale because of a simpler representation for the population, especially for groups that received little or no instruction. Values transformation was done at the time of the statistical analysis.

\section{Psychometric properties}

A total of 92 patients with diabetes were recruited. Their mean age was $56.4 \pm 10.9$ (range 33-90). Our sample was constituted predominantly by women. More than half of the participants did not receive any formal education. In $3 / 4$ 
of the case, diabetes duration exceeded 5 years. The most reported complication was retinopathy. The characteristics of the participants are summarized (Table 1).

Very few missing values were found except for the "sexual functioning" domain. This domain also showed the highest ceiling and floor effect. Mean scores for the Moroccan diabetes-39 domains ranged from $28.9 \pm 16.8$ for "social burden" and $60.4 \pm 24.7$ for "anxiety and worry". Descriptive statistics of the five domains are reported (Table 2).

Cronbach's alpha exceeded 0.7 for four out of the five domains. The highest value was 0.93 for "diabetes control" and the lowest value was 0.65 for "social burden". Most values of inter-item correlation within each domain were moderate to high although some values were low (Table 3). Items showed higher correlations with their own domain as compared to the other domains supporting item discriminate validity (Table 3). As hypothesized, higher scores of the five domains of the diabetes-39 were associated with the perception of lower quality of life and higher disease severity. All associations were significant except for the "sexual functioning" domain with the perception of disease severity (Table 4).

\begin{tabular}{|l|l|l|}
\hline & Number (n) & Percentage (\%) \\
\hline Age (year) & & \\
\hline$<50$ & 22 & 23.9 \\
\hline $50-60$ & 36 & 39.1 \\
\hline$>60$ & 34 & 37.0 \\
\hline Sex & & \\
\hline Men & 24 & 26.1 \\
\hline Women & 68 & 73.9 \\
\hline Education (n= 89) & & \\
\hline None & 50 & 56.3 \\
\hline Primary school & 28 & 31.4 \\
\hline Secondary school and beyond & 11 & 12.3 \\
\hline Health insurance & 80 & 88.9 \\
\hline Duration of diabetes & & \\
\hline$<5$ & 23 & 25.0 \\
\hline $5-10$ & 37 & 40.2 \\
\hline$>10$ & 32 & 34.8 \\
\hline Treatment regimen $(\mathbf{n}=\mathbf{8 5})$ & & \\
\hline Insulin alone & 15 & 16.3 \\
\hline Oral hypoglycemics alone & 37 & 40.2 \\
\hline Combination of the two & 33 & 35.9 \\
\hline None & 7 & 7.6 \\
\hline Diabetes complications & & \\
\hline Retinopathy & 27 & 29.3 \\
\hline Nephropathy & 13 & 14.1 \\
\hline Neuropathy & 3 & 3.3 \\
\hline
\end{tabular}

Table 1: Description of the study participants' characteristics. 


\begin{tabular}{|l|l|l|l|l|l|l|}
\hline Domain & $\begin{array}{l}\text { Number } \\
\text { of missing } \\
\text { values }\end{array}$ & Median & Mean & SD & Minimum/Maximum & $\begin{array}{l}\text { Ceiling/Floor } \\
(\boldsymbol{\%})^{\mathbf{a}}\end{array}$ \\
\hline Diabetes control & 1 & 44.5 & 46.8 & 20.8 & $12.9 / 92.9$ & $3.3 / 2.2$ \\
\hline Anxiety and worry & 0 & 60.4 & 58.8 & 24.7 & $12.9 / 92.9$ & $5.4 / 9.8$ \\
\hline Social burden & 2 & 28.9 & 32.6 & 16.8 & $8.9 / 84.9$ & $1.1 / 1.1$ \\
\hline Sexual functioning & 31 & 46.2 & 47.8 & 27.2 & $12.9 / 92.9$ & $24.6 / 11.5$ \\
\hline Energy and mobility & 0 & 56.9 & 54.1 & 20.1 & $11.5 / 92.9$ & $1.1 / 1.1$ \\
\hline
\end{tabular}

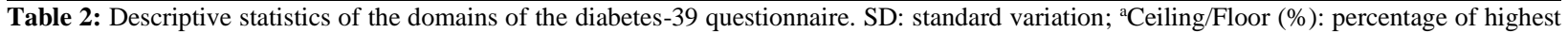
and lowest scores.

\begin{tabular}{|l|l|l|l|l|l|}
\hline Domain & $\begin{array}{l}\text { Number } \\
\text { of items }\end{array}$ & $\begin{array}{l}\text { Cronbach's } \\
\text { alpha }\end{array}$ & $\begin{array}{l}\text { Inter-item } \\
\text { correlation } \\
\text { (range) }\end{array}$ & $\begin{array}{l}\text { Item-to-domain } \\
\text { correlation } \\
\text { (range) }\end{array}$ & $\begin{array}{l}\text { Item } \\
\text { discriminative } \\
\text { validity (range) }\end{array}$ \\
\hline Diabetes control & 12 & 0.93 & $0.20 ; 0.70$ & $0.50 ; 0.84$ & $0.07 ; 0.73$ \\
\hline Anxiety and worry & 4 & 0.83 & $0.50 ; 0.68$ & $0.73 ; 0.85$ & $-0.05 ; 0.68$ \\
\hline Social burden & 5 & 0.65 & $-0.03 ; 0.60$ & $0.28 ; 0.82$ & $-0.26 ; 0.68$ \\
\hline Sexual functioning & 3 & 0.78 & $0.51 ; 0.58$ & $0.82 ; 0.83$ & $0.01 ; 0.38$ \\
\hline Energy and mobility & 15 & 0.91 & $0.20 ; 0.83$ & $0.52 ; 0.74$ & $-0.01 ; 0.66$ \\
\hline
\end{tabular}

Table 3: Internal consistency of the Moroccan version of the diabetes-39 questionnaire (Spearman's rank correlation).

\begin{tabular}{|l|l|l|l|l|l|l|}
\hline \multirow{2}{*}{ Domain } & \multicolumn{2}{|l|}{ General perception of the quality of life } & \multicolumn{2}{l|}{ Perception of disease severity } \\
\cline { 2 - 7 } & Good & Low & p & High & Low & p \\
\hline Diabetes control & $42.5 \pm 20.6$ & $54.7 \pm 19.3$ & 0.008 & $54.4 \pm 18.0$ & $32.9 \pm 18.7$ & $<0.001$ \\
\hline Anxiety and worry & $52.5 \pm 24.4$ & $70.5 \pm 20.8$ & 0.001 & $67.3 \pm 21.4$ & $44.6 \pm 22.6$ & $<0.001$ \\
\hline Social burden & $30.0 \pm 17.3$ & $37.5 \pm 14.9$ & 0.013 & $37.2 \pm 17.2$ & $24.0 \pm 11.9$ & $<0.001$ \\
\hline Sexual functioning & $43.0 \pm 25.2$ & $60.3 \pm 28.9$ & 0.031 & $51.0 \pm 25.6$ & $41.7 \pm 29.7$ & 0.172 \\
\hline Energy and mobility & $47.5 \pm 19.5$ & $66.5 \pm 14.9$ & $<0.007$ & $61.4 \pm 17.7$ & $40.4 \pm 17.4$ & $<0.001$ \\
\hline
\end{tabular}

Table 4: Association of the Moroccan version of the diabetes-39 domains and perception of the quality of life and disease severity using the MannWhitney test (domains scores presented as mean \pm standard deviations).

\section{Discussion}

In order to adapt the diabetes-39 questionnaire to the Moroccan context, we chose to translate the scale into Moroccan spoken Arabic. Despite the availability of a classical Arabic version, we believe it is difficult for many of our patients to understand it; due to substantial differences with spoken Arabic. Additionally, classical Arabic is taught at school and an important proportion of our patients are illiterate or have limited education which makes it difficult to expect an accurate assessment of patients' reported outcomes in classical Arabic. The pertinence of using the predominantly spoken language for patients' reported outcomes measurements was discussed in previous literature [27]. Also, our experience supports the use of the spoken language for our population [28].

Throughout the process of translation and adaptation, we aimed to account for the diversity of dialects in Morocco, so the adapted version is understood by most Moroccans. Sometimes, different words may be used to translate one concept, this approach was also reported by El Rhazi et al. [29]. In gathering the consensus panel, we attempted to include various profiles that allowed for a comprehensive assessment of the translated version. The input from patients was particularly enlightening concerning the comprehension of the diabetes-39 items. During this meeting, a consensus was achieved concerning the few discrepancies that have been noted. In addition to the consensus regarding 
the wording and formulation of items, two major changes were agreed upon. The adapted version adopts a formulation suitable for hetero-administration whereas originally, the scale was intended for self-administration. This choice aimed to accommodate the future use of the scale in practice among a population including elderly patients with no or limited education. The second change was adopted for the same reason and concerned the response scale which was changed from 1-7 to 1-5. This change was meant to be easier for respondents to understand and to allow us to expect more consistent responses.

Very few missing values were noted after calculating the scores for the diabetes-39 domains, except for the "sexual functioning" domain. This could be explained by a reluctancy to answer questions about sexuality in our context. Sexuality is considered taboo and related questions may be considered as sensitive as it was reported by other authors [22]. This domain was also marked by a high ceiling and floor effect as compared to the other domains.

Cronbach's alpha ranged from 0.65-0.93. Overall, the values were higher or close to 0.7 reflecting acceptable reliability. The lowest value which was noted for "social burden" is lower than values reported in previous studies $[22,30]$. Noteworthy, in the study by Khader et al., the lowest Cronbach's alpha value was also reported for the "social value" domain [22]. Thapa et al. reported a lower value for Cronbach's alpha of 0.63 for the "energy and mobility" domain [25]. In the study by Queiroz et al., the lowest Cronbach's alpha was reported for the "anxiety and worry" domain [23].

Inter-item correlations within each domain were overall moderate. On the other hand, items showed higher correlations with their domain as compared to other domains. Item internal consistency exceeded 0.4 for four domains. The lowest value was 0.28 for the "social burden" domain. Queiroz et al. also reported a higher correlation between the items and the corresponding domains [23].

In order to test for construct validity, we tested associations between the different scale domains and the general perception of the quality of life and the perception of disease severity. Overall, findings were consistent with the formulated hypotheses and support construct validity.

\section{Conclusion}

The results of this study support the reliability and validity of the Moroccan version of the diabetes-39 questionnaire. Nevertheless, further assessment of the scale in larger samples and among a more diverse population would provide additional evidence for the usefulness of this scale as a quality of life tool for patients with diabetes in our context.

\section{References}

1. International Diabetes Federation. IDF Diabetes Atlas 9th edition 2019.

2. World Health Organization. Global report on diabetes: executive summary.

3. Tazi MA, Abir-Khalil S, Chaouki N, et al. Prevalence of the main cardiovascular risk factors in Morocco: results of a National Survey, 2000. J Hypertens. 2003;21(5):897-903.

4. Chetoui A, Kaoutar K, Kardoudi A, et al. Epidemiology of diabetes in Morocco: review of data, analysis and perspectives. Int J Sci Eng Res. 2018;9(12):1310-16.

5. Sibounheuang P, Olson PS, Kittiboonyakun P. Patients' and healthcare providers' perspectives on diabetes management: A systematic review of qualitative studies. Res Social Adm Pharm. 2019;7411(18):30926-34.

6. Jiang X, Wang J, Lu Y, et al. Self-efficacy-focused education in persons with diabetes: a systematic review and meta-analysis. Psychol Res Behav Manag. 2019;12:67-79. 
7. Taylor SJ, Pinnock H, Epiphaniou E, et al. A rapid synthesis of the evidence on interventions supporting selfmanagement for people with long-term conditions: PRISMS - Practical systematic Review of SelfManagement Support for long-term conditions. NIHR Journals Library. 2014;2:53.

8. Adarmouch L, Elyacoubi A, Dahmash L, et al. Short-term effectiveness of a culturally tailored educational intervention on foot self-care among type 2 diabetes patients in Morocco. J Clin Transl Endocrinol. 2017;7:54-9.

9. Chadli A, El Aziz S, El Ansari N, et al. Management of diabetes in Morocco: results of the International Diabetes Management Practices Study (IDMPS) - wave 5. Ther Adv Endocrinol Metab. 2016;7(3):101-9.

10. Goh SG, Rusli BN, Khalid BA. Evolution of diabetes management in the 21st century: the contribution of quality of life measurement in Asians. Asia Pac J Clin Nutr. 2015;24(2):190-8.

11. Trikkalinou A, Papazafiropoulou AK, Melidonis A. Type 2 diabetes and quality of life. World J Diabetes. 2017;8(4):120-9.

12. Mikhael EM, Hassali MA, Hussain SA. Effectiveness of diabetes self-management educational programs for type 2 diabetes mellitus patients in middle east countries: a systematic review. Diabetes Metab Syndr Obes. 2020;13:117-38.

13. El Achhab Y, Nejjari C, Chikri M, et al. Disease-specific health-related quality of life instruments among adults diabetic: A systematic review. Diabetes Res Clin Pract. 2008;80(2):171-84.

14. Huang IC, Hwang CC, Wu MY, et al. Diabetes-specific or generic measures for health-related quality of life? Evidence from psychometric validation of the D-39 and SF-36. Value Health. 2008;11(3):450-61.

15. Boyer JG, Earp JA. The development of an instrument for assessing the quality of life of people with diabetes. Diabetes-39. Med Care. 1997;35(5):440-53.

16. Garratt AM, Schmidt L, Fitzpatrick R. Patient-assessed health outcome measures for diabetes: a structured review. Diabet Med. 2002;19(1):1-11.

17. Roborel de Climens A, Tunceli K, Arnould B, et al. Review of patient-reported outcome instruments measuring health-related quality of life and satisfaction in patients with type 2 diabetes treated with oral therapy. Curr Med Res Opin. 2015;31(4):643-65.

18. Khunkaew S, Fernandez R, Sim J. Demographic and clinical predictors of health-related quality of life among people with type 2 diabetes mellitus living in northern Thailand: A cross-sectional study. Health Qual Life Outcomes. 2019;17(1):177.

19. Tonetto IFA, Baptista MHB, Gomides DDS, et al. Quality of life of people with diabetes mellitus. Rev Esc Enferm USP. 2019;53:e03424.

20. Machado-Alba JE, Medina-Morales DA, Echeverri-Cataño LF. Evaluation of the quality of life of patients with diabetes mellitus treated with conventional or analogue insulins. Diabetes Res Clin Pract. 2016;116:23743.

21. Beaton DE, Bombardier C, Guillemin F, et al. Guidelines for the process of cross-cultural adaptation of selfreport measures. Spine. 2000;25(24):3186-91. 
22. Khader YS, Bataineh S, Batayha W. The Arabic version of Diabetes-39: psychometric properties and validation. Chronic Illn. 2008;4(4):257-63.

23. Queiroz FA, Pace AE, Santos CB. Cross-cultural adaptation and validation of the instrument Diabetes - 39 (D-39): brazilian version for type 2 diabetes mellitus patients - stage 1. Rev Lat Am Enfermagem. 2009;17(5):708-15.

24. Nguyen TQ, Vo TQ, Nguyen GH, et al. Assessment of health-related quality of life in patients with type II diabetes mellitus: A population-based study at a Tertiary hospital. J Clin Diagn Res. 2018;12(6):LC44-LC51.

25. Thapa S, Pyakurel P, Baral DD, et al. Health-related quality of life among people living with type 2 diabetes: a community based cross-sectional study in rural Nepal. BMC Public Health. 2019;19(1):1171.

26. Tsang S, Royse CF, Terkawi AS. Guidelines for developing, translating, and validating a questionnaire in perioperative and pain medicine. Saudi J Anaesth. 2017;11(Suppl 1):S80-S89.

27. Wild D, Eremenco S, Mear I, et al. Multinational trials-recommendations on the translations required, approaches to using the same language in different countries, and the approaches to support pooling the data: the ISPOR patient-reported outcomes translation and linguistic validation good research practices task force report. Value Health. 2009;12(4):430-40.

28. Adarmouch L, Sebbani M, Elyacoubi A, et al. Psychometric properties of a Moroccan version of the summary of diabetes self-care activities measure. J Diabetes Res. 2016; 2016:5479216.

29. El Rhazi K, Nejjari C, Serhier Z, et al. Cross-cultural adaptation difficulties in health quality of life scales for developing countries: example of St-George respiratory questionnaire validation in Morocco. Rev Epidemiol Sante Publique. 2009;57(3):179-89.

30. López-Carmona J, Rodríguez-Moctezuma R. Adaptation and validation of quality of life instrument Diabetes 39 for Mexican patients with type 2 diabetes mellitus 200. Salud Publica Mex. 2006;48(3):200-11. 